\title{
Sterilisation raises the commodities in Matricaria Chamomilla
}

\author{
Rafaele Maria Eidam ${ }^{1}$, Karlos Eduardo Pianoski²; Bruno Viante Almeida ${ }^{3}$; Guilherme \\ Barroso Langoni de Freitas ${ }^{4}$; Durinézio José de Almeida ${ }^{5}$.
}

\begin{abstract}
${ }^{1}$ Biomédica - Grupo de Pesquisa em Biotecnologia Translacional - Faculdade Campo Real - Guarapuava-PR.
${ }^{2}$ Mestre - Programa de Pós-graduação em Química - Universidade Estadual do Centro Oeste - Guarapuava-PR.

${ }^{3}$ Discente -Departamento Física - Universidade Estadual do Centro Oeste- Guarapuava - PR.

${ }^{4}$ Doutor, Pós-graduação em Medicina - Universidade Federal do Paraná-Curitiba - PR.

${ }^{5}$ Doutorando, Programa de Pós-graduação em Biologia Comparada da Universidade Estadual de Maringá (UEL) - Coordenador do grupo de Biotecnologia Translacional - Faculdade Campo Real.
\end{abstract}

Email: durinézio@gmail.com.br

Received: January $13^{\text {th }}, 2017$

Accepted: February $14^{\text {th }}, 2017$

Published: March $30^{\text {th }}, 2017$

Copyright $\bigcirc 2016$ by authors and Institute of Technology Galileo of Amazon (ITEGAM) This work is licensed under the Creative Commons Attribution International License (CC BY 4.0).

http://creativecommons.org/licenses/by/4.0/ (c) (1) (2) Open Actes:

\begin{abstract}
Medicinal herbs move about US\$ 22 billion a year worldwide. In chamomile we can find cyclic sesquiterpenoids as alpha-bisabolol, the farnesene, chamazulene, and matricina. As approximately 50$65 \%$ of the total composition of the oil consist in farnesenes and Bisabolol type molecules. Considering the value of the chamomile's essential oils components, this study aimed to evaluate how the different types of sterilization, which are autoclaving, microwave and ultraviolet, interfere with the essential oil composition. Our results allow us to conclude that the sterilization by autoclaving, microwave, and ultra violet light, do not degrade the main molecules and also improves the performance in hydrodistillation of essential oils from Matricaria chamomilla.
\end{abstract}

Keywords: Chamomile; Essential oil; Sterilization; Clevenger.

\section{A esterilização eleva as commodities em Matricaria Chamomilla}

\begin{abstract}
RESUMO
As plantas medicinais movimentam mundialmente cerca de US\$ 22 bilhões por ano. Na camomila podemos encontrar sesquiterpenóides cíclicos como o alfa-bisabolol o Farnezeno, Camazuleno, e a Matricina. Sendo que cerca de 50-65\% da composição total do óleo é constituída dos Farnezenos e das moléculas tipo Bisabolol. Considerando a valorização dos componentes dos óleos essenciais de camomila, este trabalho buscou avaliar o quanto, os diferentes tipos de esterilização sendo este a autoclavagem, microondas e ultravioleta, interferem na composição do óleo essencial. Nossos resultados nos permitem concluir que as esterilizações, por autoclavagem, microondas, e luz ultra violeta, não degradam as moléculas principais e melhoram o rendimento na hidrodestilação dos óleos essenciais em Matricaria chamomilla.
\end{abstract}

Palavras Chaves: Camomila; Óleo Essencial; Esterilização; Clevenger

\section{INTRODUÇÃO}

Segundo [1], vem ocorrendo um retorno ao uso de plantas medicinais e medicamentos a partir destas, em um mercado que havia sido dominado por produtos de base sintética. Como consequência, o uso de plantas medicinais assim como a fitoterapia, se encontram em expansão em todo o mundo, movimentando mundialmente cerca de US\$ 22 bilhões por ano [1].

Este setor vem atraindo cada vez mais o interesse dos países desenvolvidos, chegando os Estados Unidos a movimentar cerca de US\$ 6,5 bilhões em 2000 e a Europa US\$ 8,5 bilhões, sendo a Alemanha o maior mercado mundial [1]. 
Os compostos mais frequentes nos óleos voláteis são os monoterpenos e os sesquiterpenos. O termo, terpeno, é empregue para designar todas as substâncias cuja origem biossintética deriva de unidades do isopreno. Os terpenóides são considerados como biocomodites e constituem uma grande parte do valor atribuído a espécies vegetais de interesse farmacológico [2].

$\mathrm{Na}$ camomila (Matricaria chamomilla L) existem sesquiterpenóides cíclicos, como o alfa-bisabolol o farnezeno, camazuleno, e a matricina (3). E cerca de 50-65\% da composição total do óleo é constituída do Farnezeno e do a-bisabolol.

Em 2012, A equipe realizou ensaios experimentais com o cultivo de fungos comestíveis em plantas medicinais. Estes ensaios, resultaram em um processo efetivo de cultivo, no entanto, o cultivo deve ser precedido a uma autoclavagem.

Considerando a valorização dos componentes dos óleos essenciais de camomila, este trabalho buscou avaliar diferentes tipos de esterilização (autoclavagem, microondas e ultravioleta) e sua interferência na composição do óleo essencial.

Desta avaliação surgiu o deposito da patente no INPI (PI BR 1020120264323) sob o título "Processo para produção de cápsulas nutracêuticas, comprimidos e farinha miceliada de micélios de fungos comestíveis e medicinais a partir de substratos com plantas medicinais" que considera a possibilidade de um produto que agregue propriedades tanto de fungos quanto de plantas medicinais para efeito farmacológico.

\section{MATERIAIS E MÉTODOS}

\section{II.1 PLANEJAMENTO EXPERIMENTAL}

O experimento foi realizado nos laboratórios da Faculdade Campo Real e prosseguiu como descrito abaixo.

\section{II.1.1 PREPARAÇÃO DO MATERIAL}

Os capítulos forais, foram obtidos por compra em um mercado da região de Guarapuava, apresentando o mesmo lote e mesma origem para todos os tratamentos. Estes foram fracionados (35g para cada avaliação), identificados e armazenados há temperatura ambiente e no escuro, até o momento da realização dos demais procedimentos.

\section{II.1.2 TRATAMENTO 1 MICRO-ONDAS}

Para a esterilização em micro-ondas, dois béqueres contendo água foram colocados nos cantos do interior do microondas, no centro do aparelho foi alocada a amostra revestida em papel Kraft. O aparelho foi programado para um ciclo de trabalho de 30 minutos, com pausa a cada 10 segundos para movimentação da amostra, afim de evitar danos ao material vegetal. Dado o tempo de esterilização o material foi armazenado em temperatura ambiente até prosseguir para a extração.

\section{II.1.3 TRATAMENTO 2 UV}

Para esterilização em luz ultravioleta (UV), uma câmara de controle biológico, dotada de luz ultravioleta, foi usada. A câmara foi desinfetada, com álcool $70 \%$ ficando em repouso por cinco minutos. Decorrido este tempo, as amostras foram espalhadas sobre a base de inox da câmara em uma camada fina $(\leq 1 \mathrm{~cm})$ e esterilizadas por irradiação por 30 minutos. Após esse tempo o material foi armazenado em frasco estéril e mantido em temperatura ambiente até prosseguir para a extração.

\section{II.1.4 TRATAMENTO 3 AUTOCLAVAGEM}

No processo de autoclavagem, as amostras foram acondicionadas em papel Kraft, identificadas e expostas a esterilização em autoclave a $121^{\circ} \mathrm{C}$ por 30 minutos.

O controle, foi obtido dos capítulos florais não expostos a nenhum tipo de esterilização, sendo destinados diretamente a extração.

\section{II.1.5 EXTRAÇÃO}

Foi realizada por arraste a vapor, em circuito fechado em equipamento do tipo Clevenger. $35 \mathrm{~g}$ das amostras foram usadas em $650 \mathrm{ml}$ de água destilada por um período de 5 horas. Nesse tipo de extrator, ocorre perda mínima dos voláteis (5)

\section{II.1.6 TRATAMENTO E ARMAZENAGEM DOS ÓLEOS OBTIDOS NA EXTRAÇÃO}

Os óleos obtidos das extrações, foram acondicionados em eppendorf, a este foi adicionado $1 \mathrm{ml}$ de éter etílico, para extração da umidade, a água separada foi extraída com auxílio de uma seringa graduada. Os eppendorfs foram então cobertos com papel alumínio e armazenados à $-20^{\circ} \mathrm{C}$ para preservação dos compostos.

\section{II.2 METODOLOGIA CG}

As amostras, foram analisadas em um cromatógrafo Agilent ${ }^{\circledR}$ 7890A acoplado a um detector de massas Agilent ${ }^{\circledR}$ 5975C, com ionização por impacto de elétrons a 1952,94 V, fator de ganho de 2,00 eV e uma coluna capilar apolar VF-5MS $(30 \mathrm{~m}$, $0,25 \mathrm{~mm}$ de espessura e filme de $0,25 \mu \mathrm{m}$ de $5 \%$ fenil- $95 \%$ dimetilpolisiloxano). O gás de arraste utilizado, foi o Hélio, com volume de injeção de $1,0 \mu \mathrm{L}$. A temperatura da fonte de MS foi $230{ }^{\circ} \mathrm{C}$ e do quadrupolo $150{ }^{\circ} \mathrm{C}$.

$\mathrm{O}$ espectrômetro de massa foi programado para detectar de 40,0 a 1000,0 unidades de massa atômica. A temperatura inicial da coluna foi de $190{ }^{\circ} \mathrm{C}$ mantida por 2 minutos com aquecimento de $5^{\circ} \mathrm{C}$.min- 1 até $300^{\circ} \mathrm{C}$ mantida por 2 minutos.

A identificação dos compostos, foi realizada inicialmente pela comparação dos espectros de massas, de cada componente, com aqueles fornecidos pelo banco de dados do sistema (The NIST 11 Mass Spectral Library).

Para a confirmação dos compostos, utilizou-se o valor obtido pela equação do índice de Kovats, comparado com dados da literatura.

\section{II.3 ANÁLISE ESTATÍSTICA}

Os dados foram testados quanto a comparação entre os grupos no software Statistica 8.0.

\section{RESULTADOS E DISCUSSÕES}

O óleo essencial, foi caracterizado quimicamente por uma mistura de compostos orgânicos com cerca de 120 constituintes químicos. Os nove mais representativos (figura 1), foram usados para este trabalho, todos caracterizados como de interesse farmacológico [6]. 
A camomila, apresenta suas flores reunidas em inflorescências [7]. Nos canais secretores e tricomas glandulares existentes nas inflorescências, se armazena o óleo essencial [8].

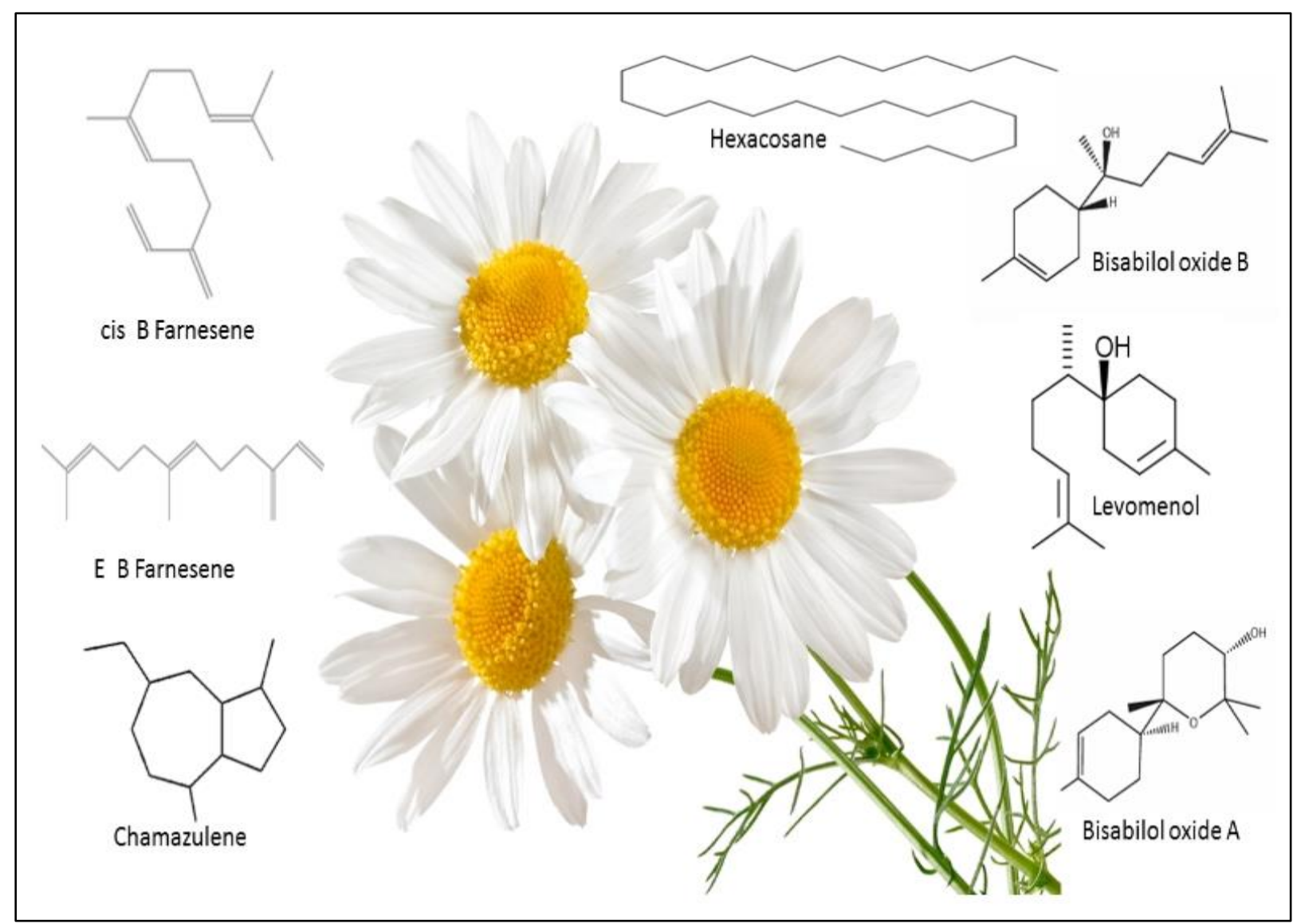

Figura 1: Representação das moléculas encontradas no capítulo floral da camomila e usadas neste trabalho. Fonte: [8].

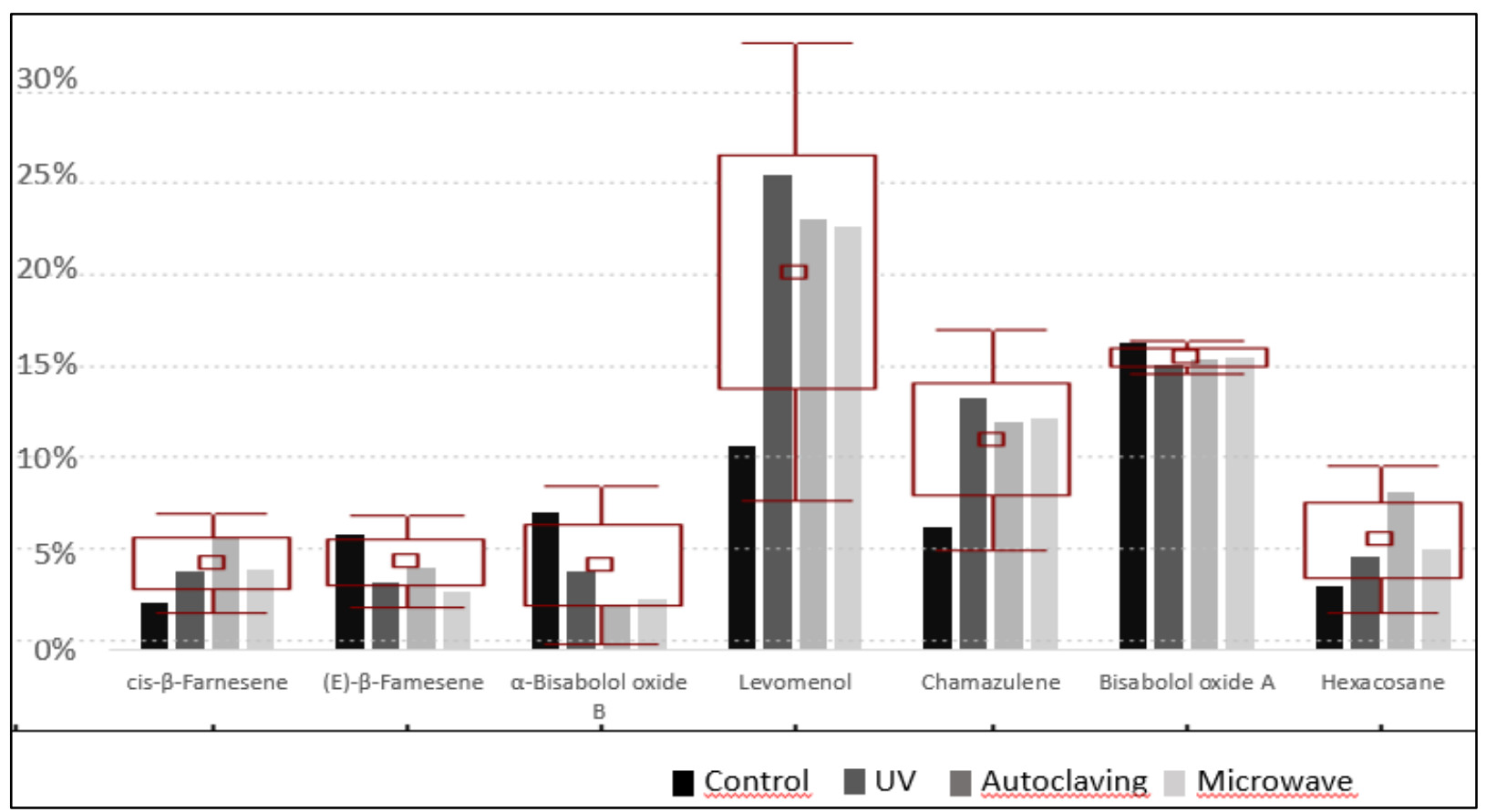

Figura 2: Boxplot; Barras; desvio padrão e média dos percentuais obtidos em nosso experimento. Fonte: Autores, (2016). 


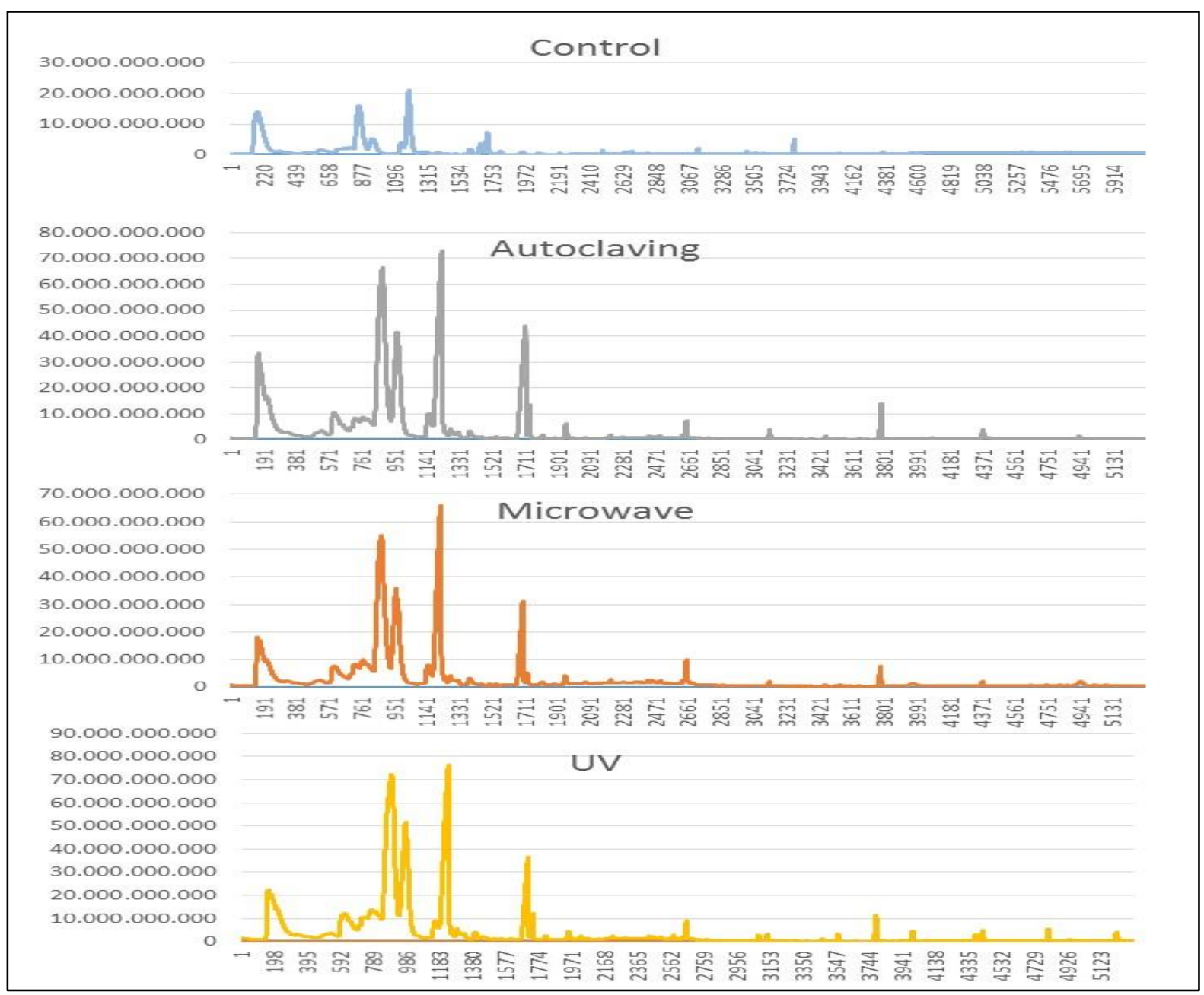

Figura 3: Cromatogramas gasosos do controle e dos três experimentos.

Fonte: Autores, (2016).

Os compostos de interesse da $M$. chamomilla, são em sua maioria voláteis, e por isso, era previsível que evaporassem no processo de esterilização. Nossos resultados, no entanto, demonstraram que os compostos, Levomenol, Cis $\beta$ Farneseno, Chamazuleno e Hexacosane, diferentemente do esperado, se apresentaram em maior teor nos tratamentos do que no controle.

O levomenol e os compostos do tipo bisabolol, são álcoois sesquiterpenos insaturado monocíclicos. Considerados, não tóxicos e não irritantes para a pele, é adequado para utilização em produtos cosmeticos de cuidados com a pele. Tem sido demonstrado possuírem propriedades anti-inflamatórias e cicatrizantes, bem como efeitos antibacterianos e antifúngicos. Especificamente, é um potente inibidor de Candida albicans e bactérias gram-positivas [9]. Suas propriedades anti-inflamatória, bactericidas e antimicóticas, o tornam um ingrediente ativo preferido para a proteção da pele contra o stress, sendo incluindo em produtos pós barba, depilação e em cremes de prevenção aos danos da exposição ao sol [10]. Na perfumaria é usado na proporção de até $0,08 \%$ para produção de parfum [11].

Os farnesenes são um conjunto de seis compostos químicos sesquiterpenos [12]. São usados na indústria como agentes aromatizantes e fragrâncias, é considerado não toxico e por isso usado como aromatizantes em alimentos [13].

Sabe-se que, quando a camomila é exposta ao processo de destilação a vapor, ocorre uma mudança molecular na matricina transformando-a principalmente em camazuleno. Neste processo, a matricina sofre uma hidrólise para um intermediário ácido hidroxicarboxílico, e com a perda de uma molécula de água, originando ácido camazulénico, em seguida, ocorre a descarboxilação do grupo carboxílico, convertendo o ácido camazulénico em chamazuleno [2]

Esse processo pode ser visto em todas as extrações realizadas dos diferentes tratamentos, mesmo na autoclavagem (temperatura de $121 \%$ h) essa molécula se manteve estável. Pré supomos que este processo se daria na esterilização e como resposta, teríamos menor teor desta molécula nos tratamentos, o que não foi observado em nossos resultados. Os chamazulenos, são um grupo dos hidrocarbonetos aromáticos policíclicos com ação anti-inflamatória, e são usados amplamente na indústria farmacêutica para este fim [14].

O hexacosane é um hidrocarboneto linear, usado na indústria como Lubrificante automotivo e aditivo de óleo lubrificante [15]. Este composto é termo estável, e era esperado que mantivesse seu teor nas amostras e no controle, no entanto os tratamentos tiveram um teor mais elevado deste composto. Atribuímos este acréscimo, á uma fragmentação dos tecidos da planta pelos processos de esterilização, o que possibilitou uma extração mais eficiente pela hidrodestilação. 


\section{CONCLUSÃO}

As esterilizações, por autoclavagem, micro-ondas, e luz ultravioleta, melhoram o rendimento na hidro destilação dos óleos essenciais em Matricaria chamomilla.

\section{REFERÊNCIAS}

[1] Almeida D.J. de; Jesus Almeida, A. P.; Dalla Santa, H.; Almeida, B. V.; Alvarez, D. C.; Freitas, G. B. Processo para produção de cápsulas nutracêuticas, comprimidos e farinha miceliada de micélios de fungos comestíveis e medicinais a partir de substratos com plantas medicinais. 2012, Brasil. Patente: Privilégio de Inovação. Número do registro: PI1020120264323, data de depósito: 16/10/2012.

[2] Petronilho, S. L. Caracterização da fracção sesquiterpénica de populações de camomila (Matricaria recutita $L$.). Dissertação (Mestrado)- Universidade de Aveiro Departamento de Química, 2008.

[3] Naz Z., Faisal M.S., Muheem A, Singh S, Ahmad J.F. Determination of (-) $\alpha$-BISABOLOL in Matricaria chamomile oil and in nanoformulation by HPTLC mhod: it's application in ex vivo studies. IAJPR. 2015; 5(6): 2190-2197.

[4] Santos, A. S.; Alves, S. D. M.; Figueiredo, F. J. C.; Neto, O. G. D. R. Descrição de Sistema e de Métodos de Extração de Óleos Essenciais e Determinação de Umidade de Biomassa em Laboratório. Ministério da Agricultura, Pecuária e Abastecimento. Belém-PA, 2004.

[5] Probst, I. S. Atividade antibacteriana de óleos essenciais e avaliação de potencial sinérgico. Dissertação (Mestrado)Universidade Estadual Paulista, Instituto de Biociências de Botucatu, 2012.

[6] Otto I, Heribert O. Patents Process for the recovery of pure alpha-bisabolol. United States Patent A US3932533. CA1013373A, CA1013373A1, DE2317583A1, DE2317583B2, DE2317583C3.1976.

[7] Otto I, Heribert O. Patents Process for the recovery of pure alpha-bisabolol United States Patent A US3932533. CA1013373A, CA1013373A1, DE2317583A1, DE2317583B2, DE2317583C3.1976.

[8] Amaral W. D. Desenvolvimento de camomila e produção de óleo essencial sob diferentes condições de manejo. Dissertação (Mestrado)- Universidade Federal do Paraná Departamento de Fitotecnia e Fitossanitarismo, 2005.

[9] Rakshit K. Devappa, Sudip K. Rakshit, Robert F.H. Dekker Forest biorefinery: Potential of poplar phytochemicals as value-added co-products. Biotechnology Advances. Volume 33, Issue 6, Part 1, 1 November 2015, Pages 681-716. doi:10.1016/j.biotechadv.2015.02.012

[10] Hartmann, K. C.; Onofre, S. B. Atividade Antimicrobiana de óleos essenciais da camomila (Matricaria chamomilla L.). Revista Saúde e Pesquisa, v.3, n.3, p.279-284, set./dez, 2010.
[11] EFSA Journal Scientific Opinion on Flavouring Group Evaluation 18, Revision 2 (FGE.18Rev2): Aliphatic, alicyclic and aromatic saturated and unsaturated tertiary alcohols, aromatic tertiary alcohols and their esters from chemical groups 6 and 8. EFSA Journal 2011;9(5):1847 [91 pp.] DOI:10.2903/j.efsa.2011.1847

[12] Hussein E., Ibrahim K A., Chaloob M.M.I. Antimicrobial activity of callus extracts derived from Chamomilla recutita $L$. seedlings and their role in curing induced skin wound infections in mice. Egypt. J. Exp. Biol. (Bot.). 2011; 7(2): 197202

[13] Salamon I, Khazaei MGaH. Chamomile biodiversity and essential oil qualitative-quantitative characteristics in Egyptian production and Iranian landraces. Emir. J. Food Agric. 2010; 22(1): 59-64. doi:10.9755/ejfa.v22i1.4907

[14] Kalsi S., Sharma S., Kaur G. Isodehydrocostus lactone and isozaluzanin C, two guaianolides from Saussurea lappa. Phytochemistry. 22, Nr. 9, $1983 . \quad$ doi:10.1016/00319422(83)80031-4.

[15] Marrufo T., Nazzaro F., Mancini E., Fratianni F., Coppola R., De Martino L., Vincenzo De A.B.A. Chemical composition and biological activity of the essential oil from leaves of Moringa oleifera Lam. cultivated in Mozambique. Feo Molecules 201301-01 PMID 24022760. 